\title{
Post-acquisition release of glutamate and norepinephrine in the amygdala is involved in taste-aversion memory consolidation
}

\author{
Kioko Guzmán-Ramos, Daniel Osorio-Gómez, Perla Moreno-Castilla, \\ and Federico Bermúdez-Rattoni ${ }^{1}$ \\ División de Neurociencias, Instituto de Fisiología Celular, Universidad Nacional Autónoma de México, México D.F. 04510, México
}

\begin{abstract}
Amygdala activity mediates the acquisition and consolidation of emotional experiences; we have recently shown that post-acquisition reactivation of this structure is necessary for the long-term storage of conditioned taste aversion (CTA). However, the specific neurotransmitters involved in such reactivation are not known. The aim of the present study was to investigate extracellular changes of glutamate, norepinephrine, and dopamine within the rat amygdala using in vivo microdialysis during the acquisition and 1-h post-acquisition of CTA paradigm. Microdialysis monitoring showed a significant norepinephrine increase related to novel taste exposure and a glutamate increase after gastric malaise induction by i.p. $\mathrm{LiCl}$ administration. Interestingly, we found a spontaneous concomitant increase of glutamate and norepinephrine, but not dopamine, 45 min after conditioning, suggesting the presence of aversive learning-dependent post-acquisition signals in the amygdala. These signals seem to be involved in CTA consolidation process, since post-trial blockade of N-methyl-D-aspartate or $\beta$-adrenergic receptors impaired long- but not short-term memory. These data suggest that CTA long-term storage involves post-acquisition release of glutamate and norepinephrine in the amygdala.
\end{abstract}

The amygdala has been established as an important locus for the processing of aversive signals and their association with a variety of cues (McGaugh et al. 2002; McGaugh 2004; Pape and Pare 2010). It has been shown that when animals associate a taste with digestive malaise, a reliable aversion for that particular taste is induced, called conditioned taste aversion (CTA). Thus, the exposure to a novel taste like saccharin solution induces neural changes in the basolateral (BLA) and central (CeA) nuclei, (Yamamoto et al. 1997), and the gastric malaise induction is related to an increase of extracellular glutamate in the BLA (Tucci et al. 1998; Miranda et al. 2002). The association between novel taste and gastric malaise is efficiently consolidated, since only one trial is required to form a long-lasting aversive taste memory.

It has been proposed that long-term stabilization of memory traces involves post-learning neuronal reactivation in the absence of sensory input. These processes may need reactivation of the biochemical pathways triggered by neurotransmitters release to sustain levels of protein that are required for persistence of memory. Recently, we demonstrated that the insular cortex (IC) becomes reactivated in the post-acquisition stage through glutamate and dopamine release; particularly, the reactivation of $\mathrm{N}$-metyl-D-Aspartate receptors (NMDAr) is involved in the consolidation process. Such reactivation is dependent on the amygdala functional integrity, since the temporal blockade of this structure with tetrodotoxin before the neurochemical reactivation impairs both dopamine and glutamate release in the IC and CTA consolidation (Guzmán-Ramos et al. 2010).

There is evidence that catecholamines have strong modulatory influences in the consolidation process within post-learning periods (LaLumiere et al. 2004; LaLumiere and McGaugh 2005). It has been reported that post-trial infusions of antagonist

\footnotetext{
${ }^{1}$ Corresponding author.
}

E-mail: fbermude@ifc.unam.mx.

Article is online at http://www.learnmem.org/cgi/doi/10.1101/Im.024703.111. or agonists of $\beta$-adrenergic receptors, impaired or enhanced, respectively, inhibitory avoidance consolidation (Gallagher et al. 1977; Ferry and McGaugh 1999). In the CTA paradigm, norepinephrine within the amygdala seems to play a critical role during the acquisition stage (Miranda et al. 2003), but there is scarce information about the modulatory effects on post-acquisition stages in order to consolidate the taste memory trace.

Therefore, the purpose of the present study was to evaluate by in vivo microdialysis the release of glutamate, norepinephrine, and dopamine during the presentation of taste and inducing malaise agents, and during a 60-min period after the association phase has occurred. In addition, we tested whether such post-acquisition events would have a functional role in long-term memory stabilization.

\section{Results}

In order to evaluate glutamate, norepinephrine, and dopamine release in the amygdala, the following groups of animals were submitted to in vivo microdialysis monitoring during stimuli exposure and one extra hour. The conditioned group (SAC-LiCl $n=6)$, was exposed for $15 \mathrm{~min}$ to $10 \mathrm{~mL}$ of a $0.1 \%(\mathrm{wt} / \mathrm{vol})$ sodium saccharin solution, followed by an i.p. $\mathrm{LiCl}$ injection $(0.4 \mathrm{M}, 7.5 \mathrm{~mL} / \mathrm{kg}) 15 \mathrm{~min}$ later. Rats in the nonconditioned group (SAC-NaCl, $n=6$ ) were exposed to the same saccharin solution, but afterward they received an i.p. $\mathrm{NaCl}$ injection $(0.4 \mathrm{M}$, $7.5 \mathrm{~mL} / \mathrm{kg}$ ) that does not cause gastric malaise and, therefore, no taste aversion developed. Another control group of animals was exposed to tap water instead of saccharin and received the $\mathrm{LiCl}$ injection after $15 \mathrm{~min}$ to rule out the possible effects of $\mathrm{LiCl}$ by itself ( $\mathrm{H} 2 \mathrm{O}-\mathrm{LiCl}, n=7)$. Finally, the backward conditioned group (LiCl-SAC, $n=6$ ) was exposed to a $\mathrm{LiCl}$ injection $(0.4 \mathrm{M}$, $7.5 \mathrm{ml} / \mathrm{kg}$ ) and $15 \mathrm{~min}$ later the saccharin solution was presented, resulting in an ineffective training for CTA memory formation (Barker and Smith 1974; Guzmán-Ramos et al. 2010). 


\section{Release of glutamate during CTA training and post-acquisition period}

The baseline concentration of glutamate was $2.34 \pm 0.23 \mathrm{pmol} /$ $\mu \mathrm{L}$ in the microdialyzed groups. Two-way ANOVA analysis of glutamate monitoring indicated a significant difference among groups (SAC-LiCl group and its control groups SAC-NaCl, H2O-LiCl, and LiCl-SAC, $\left.F_{(3,397)}=5.604, P<0.01\right)$ and among fractions $\left(F_{(20,397)}=3.695, P<0.01\right)$. Figure $1 \mathrm{~A}$ shows no changes in glutamate release in the amygdala during the saccharin presentation in both the SAC-LiCl (conditioned group) and the $\mathrm{SAC}-\mathrm{NaCl}$ group. Analysis of the glutamatergic changes in the SAC-LiCl group showed differences among fractions, particularly the administration of $\mathrm{LiCl} 0.4 \mathrm{M}$ induced a significant increase in glutamate release in the 45 -min fraction $\left(F_{(20,97)}=3.228, P<\right.$ 0.01 ), while in the SAC- $\mathrm{NaCl}$ group the administration of an equimolar solution of $\mathrm{NaCl}$ was not able to induce it $\left(F_{(3,20)}=\right.$ 2.923, $P<0.05$, SAC-LiCl vs. SAC-NaCl in the $45-\mathrm{min}$ fraction). Interestingly, post-hoc analysis in the 85-min fraction during post-acquisition monitoring revealed a significant increase in glutamate in the SAC-LiCl group, but not in the SAC-NaCl or in other control groups $\left(F_{(3,18)}=4.031, P<0.05\right)$. To rule out that the $\mathrm{LiCl}$ administration alone is involved in the post-acquisition increment, we compared the glutamate release of the conditioned group with another control group that tasted tap water instead of saccharin before the $\mathrm{LiCl}$ i.p. injection $(\mathrm{H} 2 \mathrm{O}-\mathrm{LiCl})$. As we can see in Figure 1B, glutamate levels remained unaffected by the water intake, and the subsequent $\mathrm{LiCl}$ administration induced glutamate increases $\sim 250 \%$ of baseline release $\left(F_{(20,107)}=2.608\right.$, $P<0.01$ in fraction $45 \mathrm{~min})$. However, no post-acquisition changes were seen in this group, indicating that $\mathrm{LiCl}$ administration alone, without previous SAC exposure, did not induce postacquisition glutamate increase. We also evaluated and monitored a group that underwent backward conditioning; in this protocol the CS is preceded by the US presentation and CTA cannot be established (see Figs. 1C, 2). In this group, the $\mathrm{LiCl}$ administration also induced a significant glutamate release $\left(F_{(20,93)}=2.897, P<\right.$ 0.01 in fraction $20 \mathrm{~min}$ ) and the saccharin solution had no effect on extracellular glutamate. Nevertheless, the post-acquisition glutamate increments were not present, proving that only the CS-US forward conditions induce glutamate post-learning activity.

\section{Release of norepinephrine during CTA training and post-acquisition period}

The baseline concentration of norepinephrine was $5.23 \pm 0.53$ $\mathrm{fmol} / \mu \mathrm{L}$. Statistical analysis made by two-way ANOVA revealed significant differences among groups $\left(F_{(3,382)}=6.172, P<0.01\right)$ and among fractions $\left(F_{(20,382)}=6.460, P<0.01\right)$. During the monitoring of CTA acquisition (Fig. 1D), a significant increment of $\sim 300 \%$ of baseline was found in the 25 -min fraction during exposure to the saccharin solution $\left(F_{(20,98)}=2.107, P<0.01\right)$ in the SAC-LiCl group. In the $\mathrm{SAC}-\mathrm{NaCl}$ group, significant changes in norepinephrine related to the saccharin exposure were also found $\left(F_{(20,100)}=4.083, P<0.01\right)$. In both groups the $\mathrm{LiCl}$ and $\mathrm{NaCl}$ administration (fraction $45 \mathrm{~min}$ ) induced transient and similar increment of extracellular norepinephrine (SAC-LiCl group $F_{(20,98)}=2.107, P<0.01$ and in $\mathrm{SAC}-\mathrm{NaCl}$ group $F_{(20,100)}=$ $4.083, P<0.01)$. However, the continuous post-acquisition monitoring revealed a $210 \%$ increase exclusively in the SAC-LiCl at $45 \mathrm{~min}$ after $\mathrm{LiCl}$ injection (85-min fraction, $F_{(3,17)}=2.527, P<$ $0.05)$. Therefore, this increment was significantly different from the $\mathrm{SAC}-\mathrm{NaCl}$ and the other control groups that did not develop taste aversion (see Fig. 2). It is noteworthy that even though both SAC-LiCl and SAC-NaCl groups showed the same noradrenergic increments related to the CS-US presentation, only the
SAC-LiCl group elicited the post-acquisition release. Significant changes of norepinephrine were found in the $\mathrm{H} 2 \mathrm{O}-\mathrm{LiCl}$ control group (Fig. 1E), $\left(F_{(20,102)}=3.709, P<0.01\right)$. The water presentation did not elicit norepinephrine release, unlike a novel taste exposure such as saccharin that did produce a significant norepinephrine release (Fig. 1D); thus, the only noradrenergic change found in this group was related to $\mathrm{LiCl}$ administration $\left(F_{(20,102)}=3.709, P<0.01\right.$ in fraction $\left.45 \mathrm{~min}\right)$. Although the backward conditioned group showed significant norepinephrine changes $\left(F_{(20,90)}=2.174, P<0.01\right)$ with the administration of LiCl $\left(F_{(20,90)}=2.174, P<0.01\right.$ in fraction 20 min compared with baseline fractions) and saccharin solution presentation $\left(F_{(20,90)}=\right.$ $2.174, P<0.05$ in fraction $45 \mathrm{~min}$ ), the post-acquisition activity was absent (Fig. 1F). This finding is in agreement with the fact that the groups that did not acquire CTA learning did not show the neurochemical reactivation.

\section{Release of dopamine during CTA training and post-acquisition period}

Basal concentration of dopamine was $6.35 \pm 0.13 \mathrm{fmol} / \mu \mathrm{L}$. Although overall analysis showed no significant differences among groups $\left(F_{(3,394)}=2.213, P=0.086\right)$ and among fractions $\left(F_{(20,394)}=1.146, P=0.29\right)$. As it can be seen (Fig. $\left.1 G-I\right)$, no significant post-acquisition increments of dopamine were present in any behavioral condition, suggesting that this neurotransmitter may not be involved in CTA consolidation in terms of neurochemical reactivation in the amygdala.

\section{Behavioral results}

Three days after training, aversion memory was evaluated by reexposing the animals to the saccharin solution, and their consumption was measured.

As we have seen in Figure 2, the behavioral results showed that the conditioned SAC-LiCl group produced a significant and clear taste aversion. On the contrary, the H2O-LiCl, SAC-NaCl, and the backward conditioning (LiCl-SAC) control groups failed to elicit reliable CTA. The ANOVA test showed significant differences among groups. $\left(F_{(3,20)}=34.1101, P<0.0001\right)$ and a post hoc analysis indicated that the saccharin consumption in the LTM test of the SAC-LiCl group was significantly different from the rest of the control groups $\left(P^{\prime} \mathrm{s}<0.0001\right)$.

\section{Post-trial blockade of NMDA and $\beta$-adrenergic receptors impairs CTA consolidation}

Our microdialysis results indicate that there is post-acquisition activity of glutamate and norepinephrine in the amygdala after CS-US association. Therefore, we evaluated the functional role of such post-acquisition neurochemical changes by blocking either the NMDA glutamate receptors (APV, $10 \mu \mathrm{g} / \mu \mathrm{L}$ ) or the $\beta$-adrenergic receptors (propranolol, $5 \mu \mathrm{g} / \mu \mathrm{L}$ ) $30 \mathrm{~min}$ after the acquisition period. A simple ANOVA analysis showed no significant difference among groups in the STM test, indicating that drug administration did not impair the task acquisition (Fig. 3). However, significant differences were found among groups in the LTM test, as revealed by one-way ANOVA analysis $\left(F_{(2,49)}=16.563, P<\right.$ $0.0001)$. Post-hoc Fisher test showed that LTM was impaired in the NMDAr-inhibited group (APV), as it was significantly different from the saline group (SS), which developed a clear long-term aversion $(P<0.01)$. The group that received intra-amygdalar propranolol (PROP) also showed differences in the LTM test compared with the SS group $(P=0.0015)$. However, the LTM consumption of the PROP group was significantly different from the APV group $(P=0.0071)$, indicating that although postacquisition activity of both NMDAr and $\beta$-adrenergic receptors 
GLUTAMATE

\section{A}

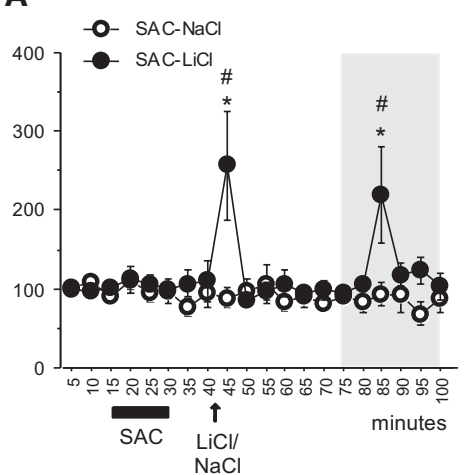

B

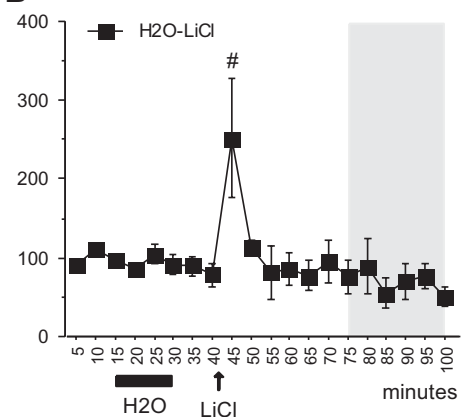

\section{C}

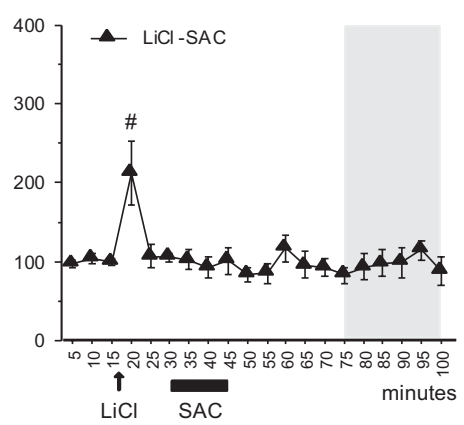

NOREPINEPHRINE

D

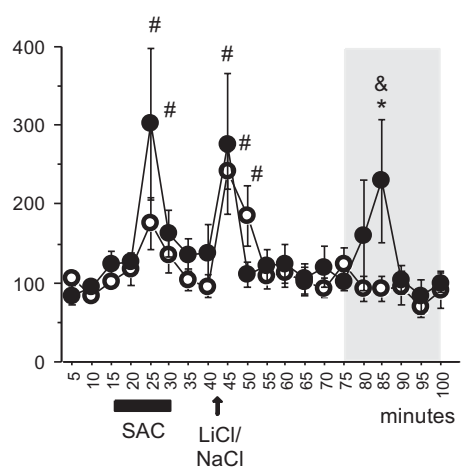

\section{E}

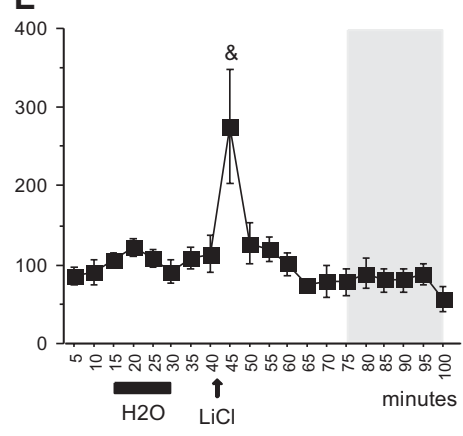

F

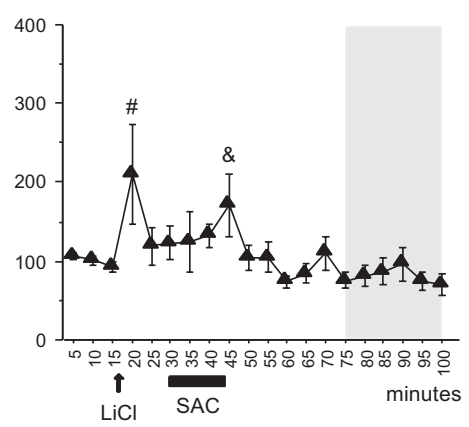

DOPAMINE

G

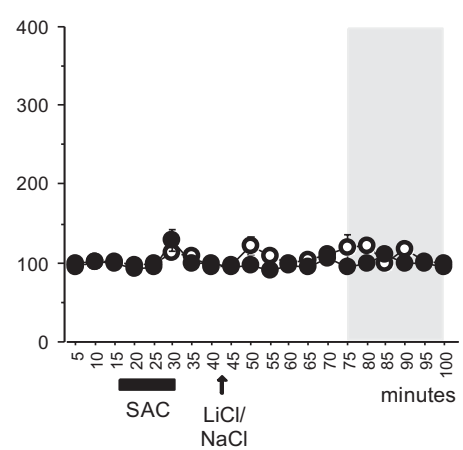

H

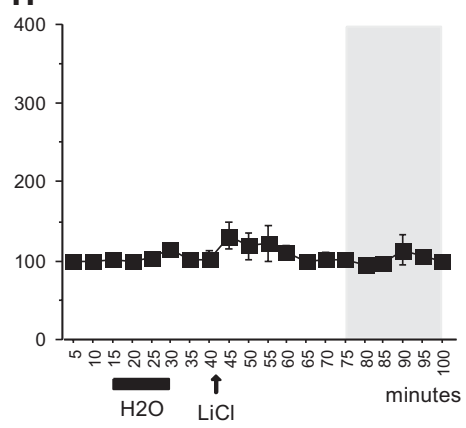

I

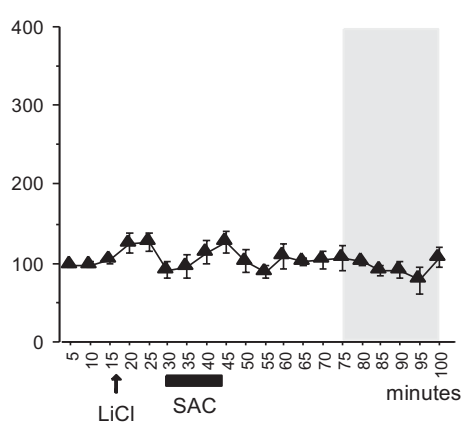

Figure 1. Extracellular glutamate and norepinephrine levels in the amygdala increase concomitantly in the post-acquisition period of CTA training. ( $A$ ) Glutamate monitoring: SAC-LiCl, conditioned group received $0.1 \%$ saccharin solution followed by $0.4 \mathrm{M} \mathrm{LiCl} \mathrm{i.p.} \mathrm{injection}(7.5 \mathrm{~mL} / \mathrm{kg})$; SAC-NaCl, nonconditioned control group received $0.1 \%$ saccharin solution, followed by $0.4 \mathrm{M} \mathrm{NaCl}$ i.p. injection $(7.5 \mathrm{~mL} / \mathrm{kg})$. The US elicited a glutamate increase after the $\mathrm{LiCl}$, but not after $\mathrm{NaCl}$ administration. Note that only the conditioned group showed a post-acquisition increase in the 85-min fraction. (B) Glutamate response in a control group that received tap water, followed by $0.4 \mathrm{M} \mathrm{LiCl} \mathrm{i.p.} \mathrm{(H2O-LiCl).} \mathrm{(C)} \mathrm{Glutamate} \mathrm{response} \mathrm{during} \mathrm{the} \mathrm{backward} \mathrm{conditioning}$ (LiCl-SAC) received $0.4 \mathrm{M} \mathrm{LiCl}$ i.p. and later a $0.1 \%$ (wt/vol) saccharin solution; there is no post-acquisition increment. (D) Norepinephrine monitoring during CTA training and 1-h post-acquisition period; exposure to a novel taste induced norepinephrine increase, as well as after both $\mathrm{LiCl}$ and $\mathrm{NaCl}$ i.p. injections. However, only the conditioned group showed a post-acquisition increase in the 85-min fraction. (E) Norepinephrine responses in the $\mathrm{H} 2 \mathrm{O}-\mathrm{LiCl}$ group, $\mathrm{LiCl}$ induces a significant increase. $(F)$ Despite the fact that norepinephrine responded to $\mathrm{LiCl}$ and saccharin in the backward conditioning, no postacquisition release was observed. $(G)$ Dopamine monitoring during CTA training and 1-h post-acquisition period, no significant changes were found in the SAC-LiCl or SAC-NaCl group. (H) Dopamine responses in $\mathrm{H} 2 \mathrm{O}-\mathrm{LiCl}$ group. (I) Dopamine responses on backward conditioning control group (LiCl-SAC). Graphics expressed as means of \% baseline release \pm SEM. $\left(^{*}\right) P<0.05$ vs. control group; $(\#) P<0.01 ;(\&) P<0.05$ vs. baseline release.

is involved in the CTA consolidation process, the NMDAr blockade caused a larger impairment, leading to the consumption of almost $100 \%$ of the saccharin consumed during acquisition.

\section{Verification of probes and cannulae placement}

Figure 4 presents a microphotograph of the location of the microdyalisis probes and cannulae aimed at the amygdala. In all groups the rats included in the microdialysis and pharmacological analy- ses had the cannulae and probes within the amygdalar complex. Three animals with erroneous guide cannulae placement from microdialysis experiments and five animals from microinjections groups were not considered in the analysis.

\section{Discussion}

The behavioral results showed that the only group having clear taste-aversion response is the one that received the forward 


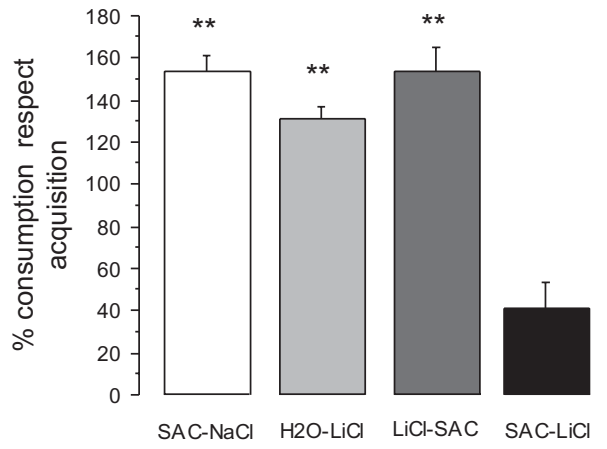

Figure 2. The conditioned group is the only one that shows aversion in a long-term memory test. The microdialyzed groups were exposed to the saccharin solution $72 \mathrm{~h}$ after stimuli exposure. For a description of the groups, see Figure 1 legend. The SAC-LiCl conditioned group showed a reliable taste aversion. However, the control groups-SAC-NaCl, H2O$\mathrm{LiCl}$, LiCl-SAC - did not show CTA. Graphics are expressed as \% of consumption of saccharin during acquisition (milliliter of saccharin during test $\times 100) / \mathrm{mL}$ saccharin during acquisition) \pm SEM. $\left({ }^{* *}\right) P<0.01$ vs. SAC-LiCl.

association between saccharin and $\mathrm{LiCl}$. In comparison, the groups that received saccharin- $\mathrm{NaCl}$ or $\mathrm{H} 2 \mathrm{O}-\mathrm{LiCl}$ presentations or LiCl-saccharin backward association did not show taste aversions. The microdialysis results showed that the presentation of a new taste induced increase in norepinephrine, but not in dopamine release. The intraperitoneal administration of $\mathrm{LiCl}$ induced increased release of glutamate, which was specific for the induction of gastric malaise, since an equimolar solution of $\mathrm{NaCl}$ did not. The post-acquisition monitoring showed a concomitant increase in norepinephrine and glutamate $\sim 45 \mathrm{~min}$ after the association of stimuli (saccharin-LiCl). Interestingly, these changes were observed only in the group that received the forward association, while the aforementioned control groups (saccharin- $\mathrm{NaCl}$, $\mathrm{H} 2 \mathrm{O}-\mathrm{LiCl}$, and LiCl-saccharin) did not show the post-acquisition activity of glutamate and norepinephrine. Finally, pharmacology results indicated that the blockade of either NMDA or $\beta$-adrenergic receptors in the amygdala $30 \mathrm{~min}$ post-acquisition impaired LTM but not STM, indicating a specific role of these receptors in CTA consolidation.

After CTA acquisition takes place, several cellular mechanisms are engaged to carry on the consolidation process. We have proposed that among the required signals for this process are post-acquisition neurochemical reactivations of the structures that were initially involved in the acquisition stage, such as the IC and the amygdala (Guzmán-Ramos et al. 2010). In this regard, we showed that the amygdala is engaged during acquisition through noradrenergic and glutamatergic responses related to the CS and US presentation, and then it becomes reactivated $\sim 45$ min later with significant release of glutamate and norepinephrine. The amygdala activity during saccharin presentation might be related to the novelty of the stimulus; several studies have reported increased amygdalar electrical activity and c-fos expression related to the exposure of new gustatory stimuli (Yamamoto et al. 1997; Nishijo et al. 2000; Fontanini et al. 2009). In terms of neurotransmitter extracellular changes, food consumption is associated with increase of acetylcholine, dopamine, and norepinephrine in the amygdala (Savard et al. 1983; Hajnal and Lenard 1997; Hajnal et al. 1998). In the present study we only found significant changes of norepinephrine, but not dopamine. In contrast, Hajnal and Lenard (1997) found that the dopamine release was associated with food consumption related to the increase of glucose and insulin levels, rather than to the novelty of the food, since the animals were tested with the same food of which they were deprived. In the present study, we found significant increases of norepinephrine with saccharin, but not with water presentation, indicating that the novelty of the gustatory stimulus, and not just the liquid consumption, could be causing the noradrenergic response. In this regard, it has been demonstrated that intraamygdalar injection of norepinephrine before taste exposure increases the preference for the familiar tastes over novel gustatory stimuli, i.e., increasing the neophobic response (Borsini and Rolls 1984). Novel stimuli represent relevant cues for aversive or appetitive outcomes, and amygdalar activity may modulate the strength of the association stimulus-consequence through the noradrenergic system. Our results also indicate that novel taste stimulus does not produce extracellular changes in glutamate within the amygdala, which is in accordance with previous results (Tucci et al. 1998; Miranda et al. 2002). In summary, amygdala norepinephrine but not glutamate or dopamine release seems to be related with the relevance or salience of the novel stimulus presentation.

The amygdala activity during the gastric malaise induction has been well documented (Yamamoto et al. 1997; Miranda et al. 2002; Bermudez Rattoni 2004; Bernstein and Koh 2007); particularly, glutamatergic activity seems to be important for the aversive signal that is associated with the previous gustatory stimulus (Tucci et al. 1998; Yasoshima et al. 2000; Miranda et al. 2002). In the present study, we confirmed that the glutamatergic increments are specific to the induction of gastric malaise, since the administration of an equimolar concentration of $\mathrm{NaCl}$ did not elicit changes in the amygdalar extracellular glutamate and failed to produce CTA memory. On the other hand, the noradrenergic signal turned out to be less specific, since both $\mathrm{NaCl}$ and $\mathrm{LiCl}$ solutions induced similar norepinephrine increments in the amygdala. The norepinephrine increase during administration of the $\mathrm{NaCl}$ solution may be part of a stress response caused by the administration of irritating solutions in the peritoneal cavity, since both $\mathrm{NaCl}$ and $\mathrm{LiCl}$ solutions were hypertonic, which
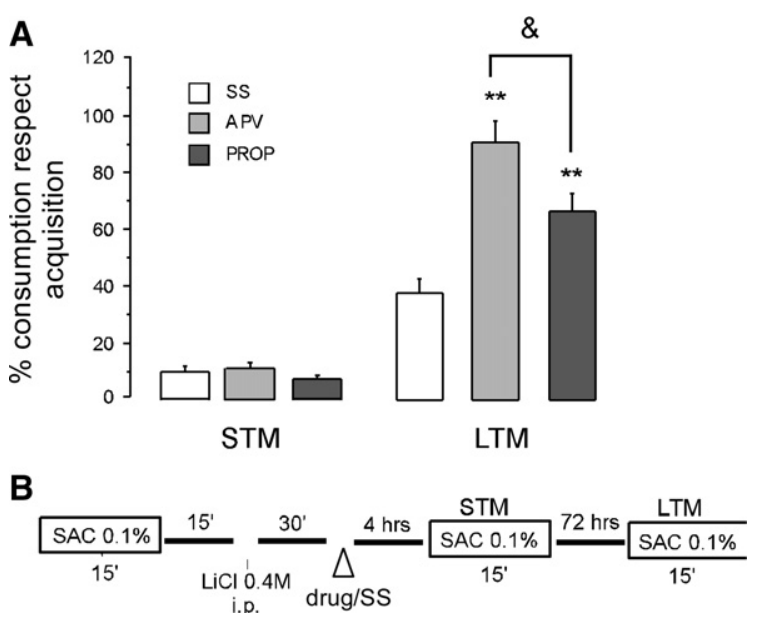

Figure 3. NMDA and $\beta$-adrenergic receptors activity during postacquisition is required for memory consolidation. (A) Effect of intraamygdalar administration of APV and Propranolol 30 min after CTA acquisition in short- and long-term memory. Post-acquisition blockade of NMDAr (APV group) or $\beta$-adrenergic receptors (PROP group) impaired CTA consolidation compared with the group that received the saline injection (SS). (B) Experimental protocol during CTA acquisition, drugs administration (white triangle), and memory tests. The results are showed in consumption of saccharin during acquisition (milliliter of saccharin during test $\times 100) / \mathrm{mL}$ saccharin during acquisition) \pm SEM. (STM) shortterm memory; (LTM) long-term memory; $(* *) P<0.01$ vs. SS group; $(\&)$ $P<0.01$ PROP vs. APV group. 


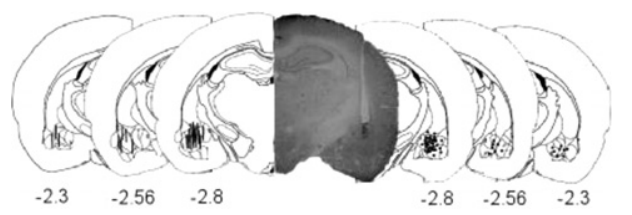

Figure 4. Representative photomicrograph of the guide cannula track aiming the amygdala and location of microdialysis membranes (lines) and tips of microinjectors (points). The numbers below indicate millimeters from bregma.

originates a nociceptive signal that activates the LC neurons (Robbins and Everitt 1995), hence inducing an elevation of norepinephrine release in the amygdala. Even though $\mathrm{NaCl}$ and $\mathrm{LiCl}$ hypertonic solutions cause nociceptive signals, only $\mathrm{LiCl}$ acts on the area postrema of the hindbrain, a structure associated with distress in the upper gastrointestinal tract (Adachi et al. 1991; Tsukamoto and Adachi 1994) producing a learned taste aversion in one trial (Garcia and Koelling 1967; Rabin and Hunt 1983). The behavioral response to lithium administration has been characterized as a general suppression of activity as well as a specific response described as "lying-on-belly," diarrhea and urination, which are not present when a $\mathrm{NaCl}$ solution is administrated (Garcia and Koelling 1967). In the case of dopamine, it has been reported that stressful stimuli, such as handling, induce an increase of dopamine release in the amygdala (Inglis and Moghaddam 1999). However, the lack of dopaminergic response during the i.p. administration may be due to the previous habituation of the animals to be handled; in fact, they did not show any signs of stress or discomfort at this time point. In summary, our results show that both norepinephrine and glutamate, but not dopamine, signal the gastric toxicity of the $\mathrm{LiCl}$, whereas the norepinephrine release may be related to the stress response induced by drinking the novel taste.

After being engaged in the acquisition of CTA, we found that amygdala reactivation involves concomitant noradrenergic and glutamatergic signals $\sim 45$ min post-acquisition, but dopamine levels did not change during this period. Interestingly, only the association between novel taste and $\mathrm{LiCl}$ produced both glutamate and norepinephrine reactivation release at $45 \mathrm{~min}$. Whereas the rest of the combinations-saccharin- $\mathrm{NaCl}, \mathrm{H} 2 \mathrm{O}-\mathrm{LiCl}$, or the backward presentation of stimuli-did not produce significant release of norepinephrine or glutamate at the 45-min post-acquisition period. It is noteworthy that even though the norepinephrine signals are very similar in the saccharin- $\mathrm{LiCl}$ and saccharin$\mathrm{NaCl}$ groups, only the saccharin- $\mathrm{LiCl}$ had the key aversive signal of glutamate and showed the post-acquisition norepinephrine and glutamate increments. In other words, it seems that the combination of saccharin and $\mathrm{LiCl}$ in the forward fashion will enable the amygdala reactivation. Similar results have been found in the IC for dopamine instead of norepinephrine and glutamate-that is, only when saccharin- $\mathrm{LiCl}$ pairing was presented to the animals did we observe a concomitant release of both glutamate and dopamine in the IC, around $40 \mathrm{~min}$ after the association of the stimuli (Guzmán-Ramos et al. 2010).

To demonstrate the functionality of these post-acquisition signals on memory consolidation, we administered NMDAr or $\beta$-adrenergic receptors antagonists at 30 -min post-acquisition, i.e., before the putative neurotransmitters binding in their respective receptors at $45 \mathrm{~min}$ when the observed release of both norepinephrine and glutamate occurred. The results indicated that post-acquisition blockade of the NMDAr and $\beta$-adrenergic receptors at 45-min impair CTA memory consolidation. Some reports support the notion that amygdalar NMDAr and $\beta$-adrenergic receptors play an essential role in CTA consolidation (Tucci et al.
1998; Yasoshima et al. 2000; Miranda et al. 2003); however, such blockades were made between the CS and the US presentation, affecting US processing and impairing CTA acquisition. Here we present evidence that suggest these receptors have to be reactivated after the learning period in order to consolidate CTA memory. Since the pharmacological treatments that we administrated were performed after the exposure to the CS and US, and these treatments had effect only in the LTM, it indicates a specific role of the post-learning release of these neurotransmitters in taste memory consolidation. It has been reported that the modulation of the amygdala over the IC is important for CTA consolidation. For instance, long-term potentiation induced in the BLA-IC pathway produces significant CTA memory enhancement (Escobar and Bermudez-Rattoni 2000) which depends on NMDAr activation within the IC (Escobar et al. 2002). It has also been shown that the glutamatergic activity in the amygdala during acquisition modulate the NMDAr activity in the IC at least for an hour after the pairing of the stimuli (Ferreira et al. 2005). Part of the results in the present study could explain why this could be happening; the amygdala becomes active even after the learning period through $\beta$-adrenergic and NMDAr receptors to modulate the IC post-acquisition activity. In fact, the modulation exerted by the amygdala norepinephrine in post-acquisition stages has been well documented in other aversive tasks, such as inhibitory avoidance and contextual fear conditioning, where post-training intraamygdalar infusions of norepinephrine or clenbuterol ( $\beta$-agonist) enhance memory consolidation (Introini-Collison et al. 1991, 1996; Izquierdo et al. 1992; Ferry and McGaugh 1999; LaLumiere et al. 2003; LaLumiere and McGaugh 2005). Herein, we provide evidence that in the CTA paradigm a post-acquisition activity takes place and is involved specifically in consolidation.

The actions of norepinephrine in memory consolidation may involve the activation of $\beta$-adrenergic receptors and stimulation of the cyclic AMP-dependent protein kinase (PKA)/cAMP response element binding (CREB) pathway (Liang et al. 1990; Ferry et al. 1999). PKA has been involved in regulating memory consolidation by its effects on ionic channels and ionotropic receptor conductance, particularly the NMDAr. Thus, the NMDAr are phosphorylated on the NR1 subunit, increasing the channel conductance that promotes a rise on postsynaptic $\mathrm{Ca}^{2+}$ (Tingley et al. 1997; Skeberdis et al. 2006), which in turn activates kinases and phosphatases that promote persistent changes in synaptic strength. All of this information suggests that during the postacquisition period, NMDAr and $\beta$-adrenergic receptors act in parallel to support the consolidation process. Moreover, it has also been reported that $\beta$-adrenergic receptors facilitate excitatory synaptic transmission in amygdalar pyramidal cells, so it is possible that a synergic activity could be taking place as a result of the concomitant release of norepinephrine and glutamate. The administration of a $\beta$-adrenergic agonist, such as isoproterenol, enhanced the evoked excitatory postsynaptic currents mediated by NMDAr, and this enhancement was blocked by application of Rp-adenosine $3^{\prime} 5^{\prime}$-cyclic monophosphorothioate trethylammonium salt (Rp-cAMPS), a potent PKA inhibitor (Gean et al. 1992; Huang et al. 1993, 1998; Huang and Gean 1995). Therefore, the concomitant post-acquisition increase of norepinephrine and glutamate may activate both $\beta$-adrenergic and NMDA receptors, enhancing the amygdala activity and promoting the flow of biochemical events involved in the consolidation process.

Although further studies are needed to prove the previous hypothesis, the data herein exposed indicate the relevance of the post-acquisition glutamatergic and noradrenergic activity in the amygdala. Thus, it could be possible that the amygdala needs to be reactivated after the acquisition of the task to outline the memory trace, which is consistent with the evidence that posttraining brain activity is related to previous learning experience 
(Peigneux et al. 2006; Eschenko and Sara 2008; Lansink et al. 2008; Marrone et al. 2008). Particularly in the amygdala, single-unit recordings of spontaneous activity revealed that the firing rate of BLA neurons increased gradually after inhibitory avoidance training (tone paired with footshock), peaking at 30-50 min postshock (Pelletier et al. 2005), a time frame that goes in accordance with the neurochemical reactivation herein described. Taken together, these results support the idea that keeping emotional experience in the long term requires post-acquisition amygdala activity.

In summary, our results indicate that CTA memory consolidation involves amygdala post-acquisition glutamatergic and noradrenergic activity. The concomitant release of these neurotransmitters may imply a synergic action of the $\beta$-adrenergic and the NMDA receptors, enhancing neuronal activity and promoting plastic changes that are thought to underlie memory consolidation.

\section{Materials and Methods}

\section{Subjects}

Adult male Wistar rats (bred in the Veterinarian facilities of The Institute of Cellular Physiology, Mexico), weighing 260-280 g at the time of surgery, were used and handled according to The Institute of Cellular Physiology Animal Welfare Assurance, approved by NIH in accordance with the Norma Oficial Mexicana (NOM-062-ZOO-1999) and the European Communities Council Directive of November 24th 1986 (86/609/ECC). Rats were housed individually and maintained on a 12-h light/12-h dark cycle with water and food ad libitum, except when noted on the behavioral procedures. Training was conducted during the light portion of the cycle.

\section{Guide cannulae implantation}

Animals were anaesthetized with a mixture of ketamine/xylazine $(50 \mathrm{mg} / \mathrm{kg}+5 \mathrm{mg} / \mathrm{kg})$ and placed in a stereotaxic apparatus (Stoelting). A small incision in the scalp was made and the head position was adjusted to the horizontal plane. Unilateral guide cannula (CMA Microdialysis) aimed at the amygdala was implanted using coordinates from bregma according to Paxinos and Watson (1998) (AP -2.8 mm; L - $4.8 \mathrm{~mm}$; DV -7.5 mm). The cannula was held in place with two small screws and dental cement. For the drug administration experiments, bilateral 23-gauge stainless-steel cannulae (12-mm-long, small parts) were implanted aiming to the amygdala (AP $-2.8 \mathrm{~mm}$; $\mathrm{L} \pm 4.8 \mathrm{~mm}$; DV $-6.5 \mathrm{~mm}$ ). Dummy cannulae (33-gauge, $12 \mathrm{~mm}$ ) were inserted into the guide cannulae to prevent clogging. Rats were allowed to recover from the anesthesia before being returned to their home cages.

\section{Microdialysis procedure for CS and US associative presentation}

Five days after surgery, animals were deprived of water for $24 \mathrm{~h}$ and were placed in the microdialysis chamber for $5 \mathrm{~d}$ during $3 \mathrm{~h}$ to habituate them to the environment and manipulation. All animals were allowed to drink $10 \mathrm{~mL}$ of tap water from a graded bottle during $15 \mathrm{~min}$ and another $20 \mathrm{~mL}$ in their home cages in the afternoon. During microdialysis, a dialysis probe with a 1-mm membrane (CMA 12 MD Probe, CMA Microdialysis) was connected to the micro infusion pump system (CMA Microdialysis), which infused artificial cerebrospinal fluid (ACSF, $\mathrm{NaCl} 125 \mathrm{mM}, \mathrm{KCl} 5 \mathrm{mM}, \mathrm{NaH}_{2} \mathrm{PO}_{4} \mathrm{H}_{2} \mathrm{O} 1.25 \mathrm{mM}, \mathrm{MgSO}_{4} 7 \mathrm{H}_{2} \mathrm{O}$ $1.5 \mathrm{mM}, \mathrm{NaHCO}_{3} 26 \mathrm{mM}, \mathrm{CaCl}_{2} 2.5 \mathrm{mM}$, glucose $10 \mathrm{mM}$ ) at a rate of $1 \mu \mathrm{L} / \mathrm{min}$. The length of the outflow connection tubing was measured to calculate the "dead volume" (inner volume of the tubing $\times$ length of the tubing $\times$ infusion rate), which causes a delay between the beginning of the behavioral response and the correspondent microdialysis fraction. After insertion of the probe, $1 \mathrm{~h}$ of fluid stabilization was allowed; samples were collected at a rate of $0.8 \mu \mathrm{L} / \mathrm{min}$ every $5 \mathrm{~min}$ in vials containing $0.5 \mu \mathrm{L}$ of antioxidant mixture $\left(0.25 \mathrm{mM}\right.$ ascorbic acid, $\mathrm{Na}_{2} \mathrm{EDTA}$ $0.27 \mathrm{mM}, 0.1 \mathrm{M}$ acetic acid), and immediately frozen at $-80^{\circ} \mathrm{C}$. Three fractions were collected as baseline samples before the stimulus exposure began (see below for behavioral conditions).

\section{Analysis of glutamate and norepinephrine in microdialysate samples}

The neurotransmitters concentration were determined by capillary electrophoresis as described previously (Guzmán-Ramos et al. 2010). Briefly, the procedure for microdialysis samples analysis was derivatization with $6 \mu \mathrm{L}$ of $16.67 \mathrm{M} 3$-(2-furoyl)quinoline-2-carboxaldehyde (FQ, Molecular Probes, Invitrogen) in the presence of $2 \mu \mathrm{L}$ of $\mathrm{KCN} 25 \mathrm{mM}$ in $10 \mathrm{mM}$ borate buffer $(\mathrm{pH}$ 9.2) and $1 \mu \mathrm{L}$ of internal standard $(0.075 \mathrm{mM}$ O-methyl-L-threonine, Sigma-Aldrich). The mixture was allowed to react in the dark at $65^{\circ} \mathrm{C}$ for $15 \mathrm{~min}$. Separation and analysis were conducted in a Capillary Electrophoresis system (Beckman-Coulter PACE/ MDQ, Glycoprotein System) with laser-induced fluorescence detection, light at $488 \mathrm{~nm}$ from an argon ion laser was used to excite the FQ-labeled analytes. The separation of compounds was based on a micellar electrokinetic chromatography buffer system that included $35 \mathrm{mM}$ borates, sodium dodecylsulphate $25 \mathrm{mM}$, $13 \%$ (vol/vol) methanol HPLC grade (final $\mathrm{pH} 9.6$ ). The samples were injected hydrodynamically at 0.5 psi for $5 \mathrm{sec}$ in a $75-\mu \mathrm{m}$ i.d. capillary (Beckman Coulter), then the separation was performed at $25 \mathrm{kV}$. After each sample run, the capillary was flushed with $0.1 \mathrm{M} \mathrm{NaOH}$, water and running buffer. The glutamate and norepinephrine peaks were identified by matching the migration pattern with those in a spiked sample and corrected by relating the area under the curve (AUC) of the unknown sample with the AUC of the internal standard. Data were analyzed using Karat System Gold (Beckman Coulter), generating a calibration curve of six points. All results were converted into percentage of baseline release $(\% \mathrm{BL}=$ analyte concentration $\times 100 /$ mean of the three first samples).

\section{Behavioral procedure for drugs administration experiments}

Five days after cannulae implantation, animals were deprived of water for $24 \mathrm{~h}$ and in the subsequent $5 \mathrm{~d}$ they were allowed to drink $30 \mathrm{~mL}$ of tap water for $15 \mathrm{~min}$ in the morning and $4.5 \mathrm{~h}$ later for another $15 \mathrm{~min}$ in order to perform a short-term memory (STM) and LTM test when required. This protocol for testing STM and LTM in the same animals has demonstrated that the saccharin presentation during STM has no interference with the LTM aversion response (Ferreira et al. 2005; Guzmán-Ramos et al. 2010). The volume of water ingested was measured, and the mean of this intake was considered as baseline. For CTA acquisition, rats were exposed to $0.1 \%$ (wt/vol) saccharin solution for $15 \mathrm{~min}$, and $15 \mathrm{~min}$ later they received a $0.4 \mathrm{M} \mathrm{LiCl}$ i.p. injection $(7.5 \mathrm{~mL} / \mathrm{kg})$. The STM was evaluated $4.5 \mathrm{~h}$ after the acquisition by re-exposing the rats to the same saccharin solution and registering the consumption; then LTM was evaluated $72 \mathrm{~h}$ after acquisition. Data are presented as percentage of consumption of saccharin during the test related to the saccharin consumption during acquisition (\% Consumption during acquisition = saccharin solution intake during test $\times 100 /$ saccharin solution intake during CTA acquisition).

\section{Drug administration}

All drugs were dissolved in saline solution (0.9\% wt/vol). Drug administration was made through 30-gauge dental needles that protruded $1.5 \mathrm{~mm}$ from the tip of the guide cannulae. Injection needles were connected via polyethylene tubing to two $10-\mu \mathrm{L}$ Hamilton syringes, driven by an automated micro infusion pump (Carnegie Medicine). A total volume of $1 \mu \mathrm{L}$ per hemisphere was delivered at a rate of $0.5 \mu \mathrm{L} / \mathrm{min}$. After micro infusions were completed, the injection needles were left in the guide 
cannulae for an additional minute to allow diffusion of the solutions into the tissue.

Animals were divided into three groups, counterbalanced according to their baseline mean consumption: The control group $(n=16)$ received saline solution microinjections; the APV group $(n=15)$ received DL-2-Amino-5-phosphonovaleric acid (APV, $10 \mu \mathrm{g} / \mu \mathrm{L}$; Tocris Bioscience), and the PROP group $(n=21)$ received Propranolol infusions ( $5 \mu \mathrm{g} / \mu \mathrm{L}$; Sigma-Aldrich). All groups received the intra-amygdalar microinjections $30 \mathrm{~min}$ after the CTA training and were evaluated for STM and LTM.

\section{Histology}

After the experiments were completed, rats were sacrificed with a pentobarbital overdose, and perfused intracardially with saline $0.9 \%$. Brains were removed and stored in paraformaldehyde $4 \%$ at $4^{\circ} \mathrm{C}$. They were cut in $40-\mu \mathrm{m}$ coronal slices with a freezing cryostat. Mounted slices were stained with cresyl violet, and the placement of the cannulae was verified by analyzing the slices under the light microscope. All animals with an erroneous cannulae placement were discarded from statistical analysis and final $n$-values were as described in each methodological section.

\section{Statistical analysis}

Statistical analysis of extracellular changes in the dialysates was carried out using two-way ANOVA with Fisher post-hoc test. ANOVA with post hoc Fisher test was used to analyze saccharin consumption data, a value of $P<0.05$ was considered statistically significant. Statview 4 software (Abacus Concepts) was used to perform analysis and plots.

\section{Acknowledgments}

We thank Oreste Carbajal for the technical support. This work was supported by CONACyT 060478 and DGAPA UNAM IN216709-3.

\section{References}

Adachi A, Kobashi M, Miyoshi N, Tsukamoto G. 1991. Chemosensitive neurons in the area postrema of the rat and their possible functions. Brain Res Bull 26: 137-140.

Barker LM, Smith JC. 1974. A comparison of taste aversions induced by radiation and lithium chloride in CS-US and US-CS paradigms. J Comp Physiol Psychol 87: 644-654.

Bermudez Rattoni F. 2004. Molecular mechanims of taste-recognition memory. Nat Rev Neurosci 5: 209-217.

Bernstein IL, Koh MT. 2007. Molecular signaling during taste aversion learning. Chem Senses 32: 99-103.

Borsini F, Rolls ET. 1984. Role of noradrenaline and serotonin in the basolateral region of the amygdala in food preferences and learned taste aversions in the rat. Physiol Behav 33: 37-43.

Eschenko O, Sara SJ. 2008. Learning-dependent, transient increase of activity in noradrenergic neurons of locus coeruleus during slow wave sleep in the rat: Brain stem-cortex interplay for memory consolidation? Cereb Cortex 18: 2596-2603.

Escobar ML, Bermudez-Rattoni F. 2000. Long-term potentiation in the insular cortex enhances conditioned taste aversion retention. Brain Res 852: $208-212$.

Escobar ML, Alcocer I, Bermudez-Rattoni F. 2002. In vivo effects of intracortical administration of NMDA and metabotropic glutamate receptors antagonists on neocortical long-term potentiation and conditioned taste aversion. Behav Brain Res 129: 101-106.

Ferreira G, Miranda MI, De la Cruz V, Rodriguez-Ortiz CJ, BermudezRattoni F. 2005. Basolateral amygdala glutamatergic activation enhances taste aversion through NMDA receptor activation in the insular cortex. Eur J Neurosci 22: 2596-2604.

Ferry B, McGaugh JL. 1999. Clenbuterol administration into the basolateral amygdala post-training enhances retention in an inhibitory avoidance task. Neurobiol Learn Mem 72: 8-12.

Ferry B, Roozendaal B, McGaugh JL. 1999. Basolateral amygdala noradrenergic influences on memory storage are mediated by an interaction between $\beta$ - and $\alpha 1$-adrenoceptors. J Neurosci 19: 51195123.

Fontanini A, Grossman SE, Figueroa JA, Katz DB. 2009. Distinct subtypes of basolateral amygdala taste neurons reflect palatability and reward. J Neurosci 29: 2486-2495.
Gallagher M, Kapp BS, Musty RE, Driscoll PA. 1977. Memory formation: evidence for a specific neurochemical system in the amygdala. Science 198: $423-425$.

Garcia J, Koelling RA. 1967. A comparison of aversions induced by x-rays, toxins, and drugs in the rat. Radiat Res 7: 439-450.

Gean PW, Huang CC, Lin JH, Tsai JJ. 1992. Sustained enhancement of NMDA receptor-mediated synaptic potential by isoproterenol in rat amygdalar slices. Brain Res 594: 331-334.

Guzmán-Ramos K, Osorio-Gómez D, Moreno-Castilla P, Bermúdez-Rattoni F. 2010. Off-line concomitant release of dopamine and glutamate involvement in taste memory consolidation. J Neurochem 114: 226-236.

Hajnal A, Lenard L. 1997. Feeding-related dopamine in the amygdala of freely moving rats. Neuroreport 8: 2817-2820.

Hajnal A, Pothos EN, Lenard L, Hoebel BG. 1998. Effects of feeding and insulin on extracellular acetylcholine in the amygdala of freely moving rats. Brain Res 785: $41-48$.

Huang CC, Gean PW. 1995. Cyclic adenosine-3',5'-monophosphate potentiates the synaptic potential mediated by NMDA receptors in the amygdala. J Neurosci Res 40: 747-754.

Huang CC, Tsai JJ, Gean PW. 1993. Enhancement of NMDA receptor-mediated synaptic potential by isoproterenol is blocked by Rp-adenosine 3',5'-cyclic monophosphothioate. Neurosci Lett 161: $207-210$.

Huang CC, Lin CH, Gean PW. 1998. Potentiation of N-methyl-D-aspartate currents by isoproterenol in the acutely dissociated rat amygdalar neurons. Neurosci Lett 253: 9-12.

Inglis FM, Moghaddam B. 1999. Dopaminergic innervation of the amygdala is highly responsive to stress. J Neurochem 72: 1088-1094.

Introini-Collison IB, Miyazaki B, McGaugh JL. 1991. Involvement of the amygdala in the memory-enhancing effects of clenbuterol. Psychopharmacology 104: 541-544.

Introini-Collison IB, Dalmaz C, McGaugh JL. 1996. Amygdala $\beta$-noradrenergic influences on memory storage involve cholinergic activation. Neurobiol Learn Mem 65: 57-64.

Izquierdo I, da Cunha C, Rosat R, Jerusalinsky D, Ferreira MB, Medina JH. 1992. Neurotransmitter receptors involved in post-training memory processing by the amygdala, medial septum, and hippocampus of the rat. Behav Neural Biol 58: 16-26.

LaLumiere RT, McGaugh JL. 2005. Memory enhancement induced by post-training intrabasolateral amygdala infusions of $\beta$-adrenergic or muscarinic agonists requires activation of dopamine receptors: Involvement of right, but not left, basolateral amygdala. Learn Mem 12: $527-532$

LaLumiere RT, Buen TV, McGaugh JL. 2003. Post-training intra-basolateral amygdala infusions of norepinephrine enhance consolidation of memory for contextual fear conditioning. J Neurosci 23: 6754-6758.

LaLumiere RT, Nguyen LT, McGaugh JL. 2004. Post-training intrabasolateral amygdala infusions of dopamine modulate consolidation of inhibitory avoidance memory: involvement of noradrenergic and cholinergic systems. Eur J Neurosci 20: 2804-2810.

Lansink CS, Goltstein PM, Lankelma JV, Joosten RN, McNaughton BL, Pennartz CM. 2008. Preferential reactivation of motivationally relevant information in the ventral striatum. J Neurosci 28: 6372-6382.

Liang KC, McGaugh JL, Yao HY. 1990. Involvement of amygdala pathways in the influence of post-training intra-amygdala norepinephrine and peripheral epinephrine on memory storage. Brain Res 508: $225-233$.

Marrone DF, Schaner MJ, McNaughton BL, Worley PF, Barnes CA. 2008. Immediate-early gene expression at rest recapitulates recent experience. J Neurosci 28: 1030-1033.

McGaugh JL. 2004. The amygdala modulates the consolidation of memories of emotionally arousing experiences. Annu Rev Neurosci 27: $1-28$.

McGaugh JL, McIntyre CK, Power AE. 2002. Amygdala modulation of memory consolidation: Interaction with other brain systems. Neurobiol Learn Mem 78: 539-552.

Miranda MI, Ferreira G, Ramirez-Lugo L, Bermudez-Rattoni F. 2002. Glutamatergic activity in the amygdala signals visceral input during taste memory formation. Proc Natl Acad Sci 99: 11417-11422.

Miranda MI, LaLumiere RT, Buen TV, Bermudez-Rattoni F, McGaugh JL. 2003. Blockade of noradrenergic receptors in the basolateral amygdala impairs taste memory. Eur J Neurosci 18: 2605-2610.

Nishijo H, Ono T, Uwano T, Kondoh T, Torii K. 2000. Hypothalamic and amygdalar neuronal responses to various tastant solutions during ingestive behavior in rats. J Nutr 130: 954S-959S.

Pape HC, Pare D. 2010. Plastic synaptic networks of the amygdala for the acquisition, expression, and extinction of conditioned fear. Physiol Rev 90: $419-463$

Paxinos G, Watson C. 1998. The rat brain in stereotaxic coordinates. Academic Press, New York. 
Peigneux P, Orban P, Balteau E, Degueldre C, Luxen A, Laureys S, Maquet P. 2006. Offline persistence of memory-related cerebral activity during active wakefulness. PLoS Biol 4: e100. doi: 10.1371/journal.pbio. 0040100.

Pelletier JG, Likhtik E, Filali M, Pare D. 2005. Lasting increases in basolateral amygdala activity after emotional arousal: Implications for facilitated consolidation of emotional memories. Learn Mem 12: 96-102.

Rabin BM, Hunt WA. 1983. Effects of antiemetics on the acquisition and recall of radiation- and lithium chloride-induced conditioned taste aversions. Pharmacol Biochem Behav 18: 629-635.

Robbins T, Everitt BJ. 1995. Central norepinephrine neurons and behavior. Lippincott Williams \& Wilkins, Philadelphia, PA.

Savard P, Merand Y, Leblanc J, Dupont A. 1983. Limitation of access to highly palatable foods increases the norepinephrine content of many discrete hypothalamic and amygdaloidal nuclei of rat brain. Life Sci 33: 2513-2519.

Skeberdis VA, Chevaleyre V, Lau CG, Goldberg JH, Pettit DL, Suadicani SO, Lin Y, Bennett MV, Yuste R, Castillo PE, et al. 2006. Protein kinase A regulates calcium permeability of NMDA receptors. Nat Neurosci 9: 501-510.
Tingley WG, Ehlers MD, Kameyama K, Doherty C, Ptak JB, Riley CT, Huganir RL. 1997. Characterization of protein kinase A and protein kinase $\mathrm{C}$ phosphorylation of the N-methyl-D-aspartate receptor NR1 subunit using phosphorylation site-specific antibodies. J Biol Chem 272: $5157-5166$

Tsukamoto G, Adachi A. 1994. Neural responses of rat area postrema to stimuli producing nausea. J Auton Nerv Syst 49: 55-60.

Tucci S, Rada P, Hernandez L. 1998. Role of glutamate in the amygdala and lateral hypothalamus in conditioned taste aversion. Brain Res 813: $44-49$.

Yamamoto T, Sako N, Sakai N, Iwafune A. 1997. Gustatory and visceral inputs to the amygdala of the rat: Conditioned taste aversion and induction of c-fos-like immunoreactivity. Neurosci Lett 226: 127-130.

Yasoshima Y, Morimoto T, Yamamoto T. 2000. Different disruptive effects on the acquisition and expression of conditioned taste aversion by blockades of amygdalar ionotropic and metabotropic glutamatergic receptor subtypes in rats. Brain Res 869: 15-24.

Received October 31, 2011; accepted in revised form March 20, 2012. 


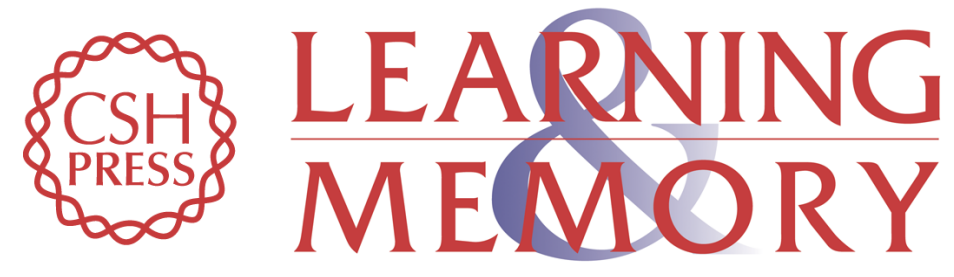

\section{Post-acquisition release of glutamate and norepinephrine in the amygdala is involved in taste-aversion memory consolidation}

Kioko Guzmán-Ramos, Daniel Osorio-Gómez, Perla Moreno-Castilla, et al.

Learn. Mem. 2012, 19:

Access the most recent version at doi:10.1101/lm.024703.111

References This article cites 47 articles, 10 of which can be accessed free at: http://learnmem.cshlp.org/content/19/6/231.full.html\#ref-list-1

License

Email Alerting

Receive free email alerts when new articles cite this article - sign up in the box at the Service top right corner of the article or click here. 